\title{
STUDY ON PYROLYSIS CHARACTERISTICS OF HUADIAN OIL SHALE WITH ISOCONVERSIONAL METHOD
}

\author{
WANG QING $^{* *}$, LIU HONGPENG, SUN BAIZHONG, \\ LI SHAOHUA
}

Northeast Dianli University, Jilin, 132012, China

\begin{abstract}
In this research, thermal decomposition of Huadian oil shale was studied by thermogravimetry (TG/DTG) at different heating rates in nitrogen environment. Apparent activation energy of the pyrolysis reaction for three samples has been determined at four heating rates (10, 20, 40, $\left.100{ }^{\circ} \mathrm{C} / \mathrm{min}\right)$ using Friedman's isoconversional method. Furthermore, the Sestak's complex mechanism was adopted to address mechanism of oil shale pyrolysis. The results showed that activation energy changes only slightly despite the fact that it is not a constant. In the conversion range of 0.1-0.9, the mean value of activation energies for samples OS1, OS2 and OS3 is 237.6, 249.61 and $242.67 \mathrm{~kJ} \cdot \mathrm{mol}^{-1}$, and their standard deviations are 2.3, 3.86 and 4.61, respectively.
\end{abstract}

\section{Introduction}

Oil shale (OS) can be defined as a compact rock of sedimentary origin with ash content of more than $33 \%$ and containing organic matter that yields oil when destructively distilled, but not appreciably when extracted with ordinary solvents [1]. As one of the important fossil fuels, OS reserves are abundant and its potential as an alternative energy source is great.

In China, the estimated reserve of OS is approximately 2 trillion tonnes, equivalent to eighty billion tonnes (bn.t) of shale oil. This magnitude ranks the 4th largest in the world, next only to US, Brazil and Estonia. At present, the total discovered reserve is $\sim 32$ bn.t, distributed mainly over 55 deposits located in provinces such as Jilin, Guangdong, Liaoning, etc. The discovered reserves in Jilin province are up to 17.6 bn.t, accounting for $56 \%$ of the State's total, which is 1.4 times sum of the primary energy resource [2]. Therefore, efficient exploitation and utilization of OS is of strategic significance to make up the deficient energy resource of Jilin province and promote development of national economy.

\footnotetext{
* Corresponding author: e-mail rszx@mail.nedu.edu.cn
} 
Thermal analysis (TA) is a typical analytical technique to describe the relationship between physical (also chemical, of course) changes and temperature. The advantages of TA include convenience, fast response and less sample needed, thus wide applications in many fields. With the improvement of thermoanalysis techniques, thermal analysis has been increasingly used as a means of determining kinetic parameters of fuel pyrolysis and combustion [3-5]. In addition, different kinetic models, such as Arrhenius, Coats \& Redfern, Horowitz \& Metzger, and Ingraham \& Marrier et al, were used to analyze TG/DTG data obtained by non-isothemal thermogravimetry [6-7].

In this work, thermogravimetry (TG/DTG) has been used to determine pyrolysis characteristics of three oil shale samples all from Huadian deposits under non-isothermal conditions. An isoconversional method was applied to determine kinetic parameters. Respective reaction models have been proposed.

\section{Experimental}

In this work, all experiments were conducted with a Perkin Elmer Pyris 1 Thermogravimetric Analyzer (TGA) at atmospheric pressure and flow rate $80 \mathrm{ml} / \mathrm{min}$ of $\mathrm{N}_{2}$ used as purge gas. Before the formal experiment, the TGA system was calibrated for temperature reading with calcium oxalate monohydrate and for buoyancy effects to allow quantitative estimation of weight changes. All the experiments were performed twice for reproducibility.

In all tests the initial samples (weight $\sim 10 \mathrm{mg}$ and the particle size $\sim 0.2 \mathrm{~mm}$ ) were prepared according to ASTM standards (D 2013). The experiments were performed at four heating rates $(10,20,40,100 \% \mathrm{~min})$ over the temperature range of $20-900{ }^{\circ} \mathrm{C}$.

Three oil shale samples taken from the $4^{\text {th }}, 5^{\text {th }}$ and $7^{\text {th }}$ seam of Gonghe mine in Huadian were designated as OS1, OS2 and OS3, respectively. The proximate and ultimate analysis of samples are shown in Table 1. It can be seen that all Huadian oil shales are high in ash content and volatile content, and fall into low-rank fuel category according to ASTM coal rank standards. With regard to its properties, it will be more economical to utilize this type of fuel in field than to transport it to other locations further from mining sites.

Table 1. Proximate and ultimate analysis of Huadian oil shales

\begin{tabular}{|c|c|c|c|c|c|c|c|c|c|c|}
\hline Sample & \multicolumn{4}{|c|}{ Proximate analysis, \% } & \multicolumn{5}{c|}{ Ultimate analysis, \% } \\
\cline { 2 - 11 } & $\mathrm{M}_{\mathrm{ad}}$ & $\mathrm{V}_{\mathrm{ad}}$ & $\mathrm{A}_{\mathrm{ad}}$ & $\mathrm{FC}_{\mathrm{ad}}$ & $\mathrm{Q}_{\text {net,ar }}, \mathrm{J} / \mathrm{g}$ & $\mathrm{C}_{\mathrm{ad}}$ & $\mathrm{H}_{\mathrm{ad}}$ & $\mathrm{N}_{\mathrm{ad}}$ & $\mathrm{O}_{\mathrm{ad}}$ & $\mathrm{S}_{\mathrm{ad}}$ \\
\hline OS1 & 5.31 & 29.76 & 60.27 & 4.66 & 8817 & 23.68 & 3.96 & 0.59 & 5.36 & 0.83 \\
OS2 & 5.52 & 26.96 & 65.45 & 2.07 & 5923 & 17.69 & 2.48 & 0.39 & 7.89 & 0.58 \\
OS3 & 5.51 & 24.21 & 69.95 & 0.33 & 4095 & 14.01 & 2.91 & 0.39 & 5.94 & 1.29 \\
\hline
\end{tabular}




\section{Methodology of kinetic measurement}

Kinetics for solid-state reactions has always been the focus of thermal analysis studies. For an Arrhenius type of kinetic equation, the primary objective is to experimentally determine the "kinetic triplet", i.e., frequency factor $A$, apparent activation energy $E_{a}$ and the reaction model, $f(\alpha)$, also called the conversion function. In the context of oil shale, there are many thermal analysis methods available in literature to process pyrolytic data, which can be divided into single and multiple scan methods [8].

The single-scan method has long been dominant in extracting kinetic data, and in application of oil shale studies [9-12]. However, several reports [13-17] showed that the single-scan methods tended to produce unreliable Arrhenius parameters, especially for non-isothermal studies. There are two major reasons for that. Firstly, in a non-isothermal study, both $T$ and $\alpha$ vary simultaneously, so that the reaction rate $K(T)$ is a function of $f(\alpha)$. As a result, almost any $f(\alpha)$ can satisfactorily fit data at the cost of drastic variations in the Arrhenius parameters, which compensates for the difference between the assumed form of $f(\alpha)$ and the true but unknown reaction model [18]. The second major reason is that solid state reaction is generally not an elementary reaction, in which the reaction model varies with temperature, and the reaction might involve several steps with different activation energies. The kinetics parameters calculated by the single-scan method do not response this point. In order to make up for these deficiencies, ICTAC proposed the Arrhenius parameters should be computed by isoconversional methods. In this paper, Friedman method was used to analyze kinetics of oil shale pyrolysis.

Usually resistance to intraparticle mass transfer and heat transfer is insignificant due to small oil shale particle size applied in studies and thus is ignored in this study. Oil shale pyrolysis is assumed to be a process controlled by kinetics, and the isoconversional method of Friedman is described as follows:

$$
\ln \left(\frac{\mathrm{d} \alpha}{\mathrm{d} t}\right)=\ln [A(\alpha) f(\alpha)]-\frac{E(\alpha)}{R T},
$$

where

$A(\alpha)$ is the frequency factor, $\min ^{-1}$,

$E(\alpha)$ is the activation energy, $\mathrm{kJ} \cdot \mathrm{mol}^{-1}$,

$\mathrm{R}$ is the gas constant,

$f(\alpha)$ is the mechanism function.

When conversion $\alpha$ in Eq. (1) is a fixed value, the relationship between $\ln (\mathrm{d} \alpha / \mathrm{d} t)$ and $1 / T$ is linear, the slopes of such plots will give the values of $(-E / R)$, and the activation energy can be obtained. This method can avoid the error arising from selection of the reaction mechanism. 


\section{Results and discussion}

\section{TG and DTG curves of oil shale pyrolysis}

Figures 1, 2 and 3 show the weight loss (TG) and differential weight loss (DTG) at different heating rates for OS1, OS2 and OS3. They exhibit similar thermal decomposition pattern. From these curves, three distinct pyrolytic stages could be ascertained.

Firstly, in lower-temperature region, from ambient temperature up to $200{ }^{\circ} \mathrm{C}$, weight loss attributes to the loss of external moisture, of interlayer water from clay minerals and decomposition of some minor mineral matters [19]. Usually, the weight loss at this stage is used to measure water content.

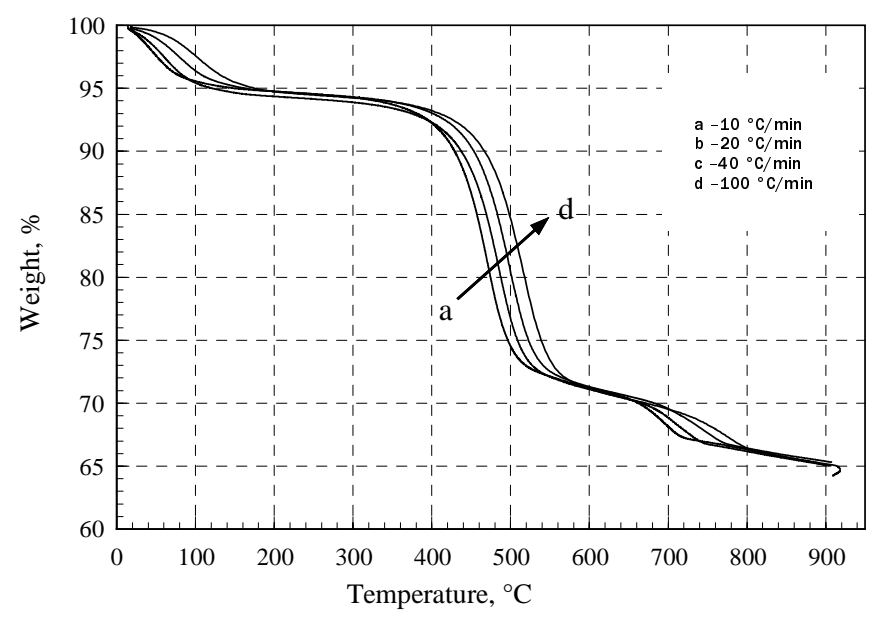

OS1-TG curves

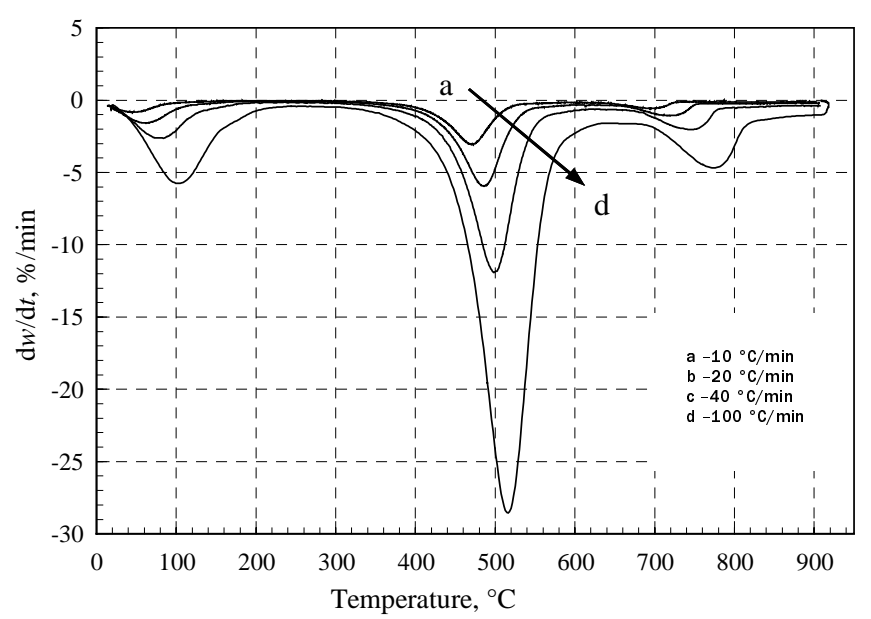

OS1-DTG curves

Fig. 1. TG and DTG curves for OS1 at various heating rates. 


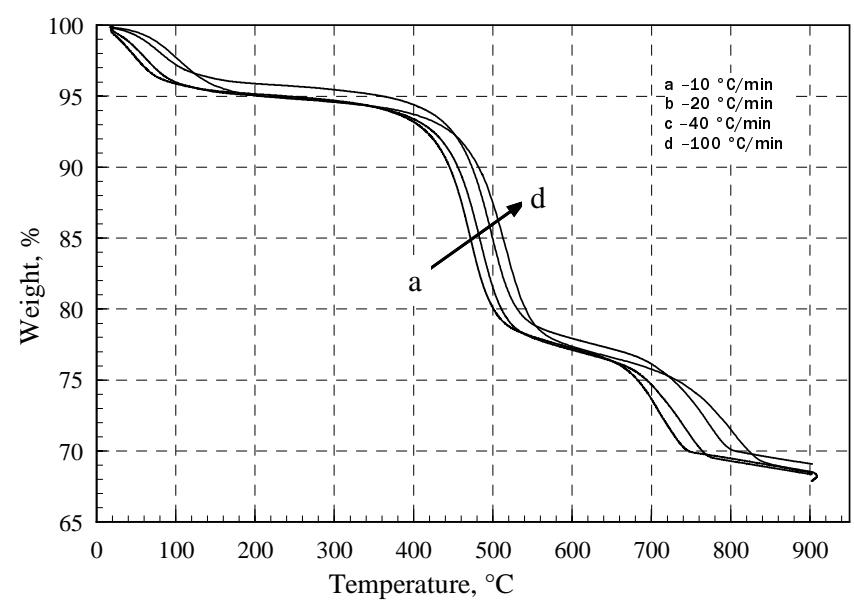

OS2-TG curves

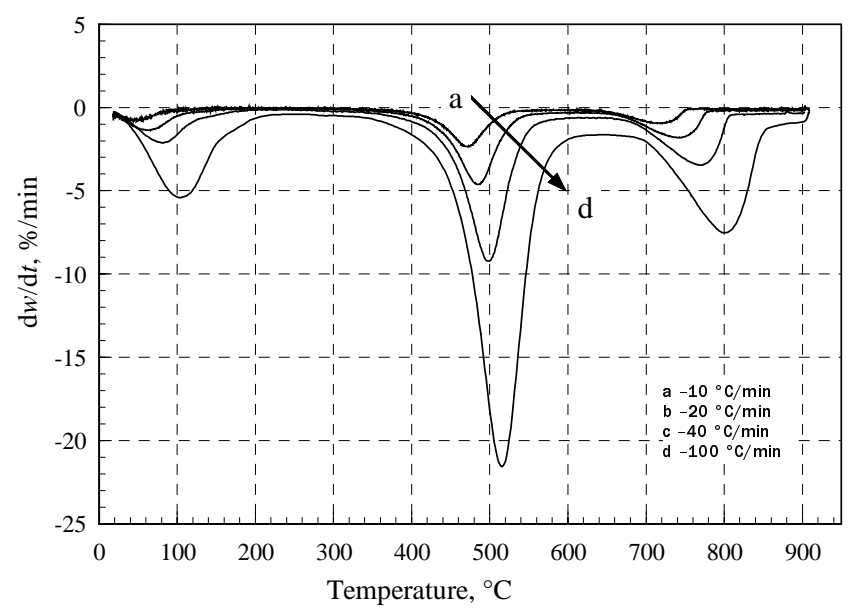

OS2-DTG curves

Fig. 2. TG and DTG curves for OS2 at various heating rates.

Secondly, at the median temperature, from 200 to $600{ }^{\circ} \mathrm{C}$, mass loss is due to the release of hydrocarbons. As shown in Fig. 3, mass loss is negligible below $320{ }^{\circ} \mathrm{C}$. Major weight loss occurs at $320{ }^{\circ} \mathrm{C}$, followed by rapid weight loss probably due to devolatization producing hydrocarbons. The weight loss in this stage is $\sim 70 \%$ of the total.

In the third stage, from 600 to $900{ }^{\circ} \mathrm{C}$, weight loss is mostly attributed to the decomposition of carbonate minerals such as calcite, dolomite and ankerite, and so on. Meanwhile $\mathrm{CO}_{2}$ produced as a result of decomposition of carbonates during this stage gasifies residual char to produce $\mathrm{CO}$, contributing to weight loss. In this stage, the rate of weight loss is distinctly lower than in the second stage. 


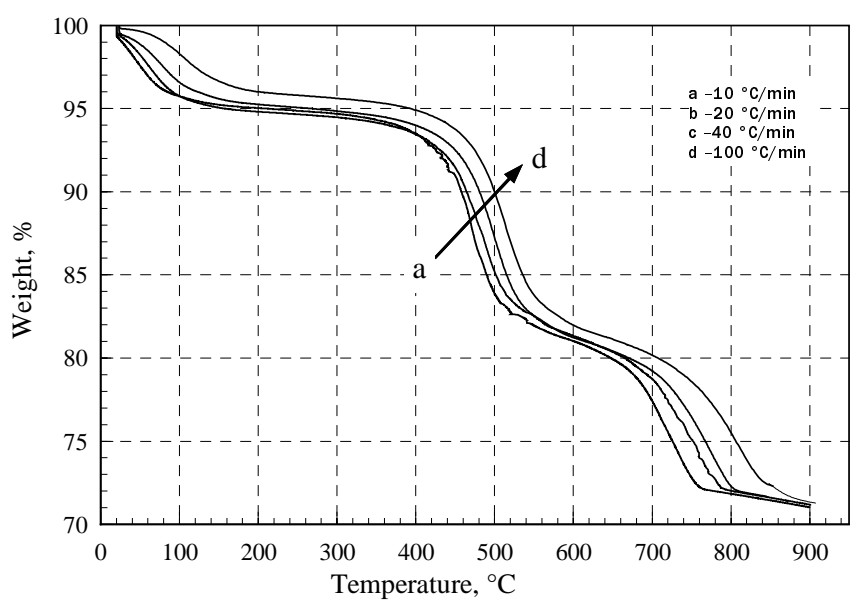

OS3-TG curves

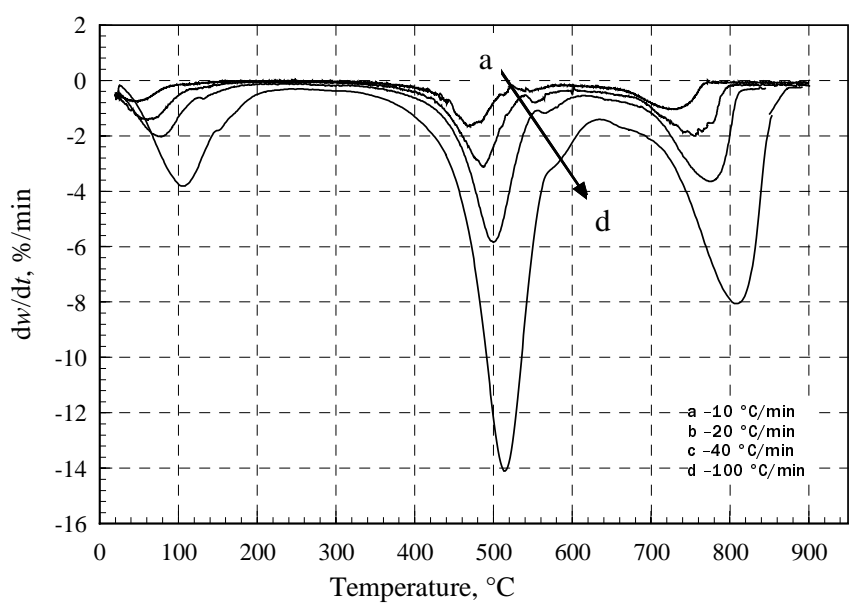

OS3-DTG curves

Fig. 3. TG and DTG curves for OS3 at various heating rates.

Table 2 gives the comparison of thermogravimetric data of oil shale samples. It can be seen that with increasing of the heating rate, $T_{p}$ increased as well. The DTG peak, which is a measure of relative reactivity (defined as the ratio of the rate of weight loss per unit of time), shifts to higher temperatures. It is caused by the variation of the rate of heat transfer with the change in the heating rate and the short exposure time to a certain temperature at a higher heating rate, as well as the kinetics of decomposition. Heating rate also affects the weight loss at a certain temperature. For example, at the same temperature, the lower the heating rate, the more the volatile material evolved. 
Table 2. Comparison of thermogravimetric data of oil shale samples

\begin{tabular}{|c|c|c|c|c|c|c|c|}
\hline \multirow[t]{2}{*}{ Sample } & \multirow{2}{*}{$\begin{array}{c}\beta \\
\left({ }^{\circ} \mathrm{C} / \mathrm{min}\right)\end{array}$} & \multicolumn{2}{|c|}{$25-200{ }^{\circ} \mathrm{C}$} & \multicolumn{2}{|c|}{$200-600^{\circ} \mathrm{C}$} & \multicolumn{2}{|c|}{$600-900{ }^{\circ} \mathrm{C}$} \\
\hline & & $w, \%$ & $T_{p},{ }^{\circ} \mathrm{C}$ & $w, \%$ & $T_{p},{ }^{\circ} \mathrm{C}$ & $w, \%$ & $T_{p},{ }^{\circ} \mathrm{C}$ \\
\hline \multirow{4}{*}{ OS1 } & 10 & 5.3 & 36 & 23.8 & 471 & 4.8 & 506 \\
\hline & 20 & 5.7 & 63 & 23.6 & 486 & 5.7 & 516 \\
\hline & 40 & 5.3 & 76 & 23.5 & 498 & 5.9 & 530 \\
\hline & 100 & 5.3 & 105 & 23.6 & 516 & 6.9 & 552 \\
\hline \multirow{4}{*}{ OS2 } & 10 & 4.8 & $55^{-}$ & 23 & 474 & 3.8 & 498 \\
\hline & 20 & 4.8 & 65 & 18.1 & 487 & 8.7 & 515 \\
\hline & 40 & 4.1 & 73 & 18 & 499 & 8.8 & 526 \\
\hline & 100 & 5.0 & 106 & 17.6 & 519 & 9.5 & 562 \\
\hline \multirow{4}{*}{ OS3 } & 10 & 5.0 & 54 & 14.0 & 471 & 10.0 & 739 \\
\hline & 20 & 5.2 & 66 & 13.5 & 488 & 10.1 & 760 \\
\hline & 40 & 4.8 & 81 & 14.0 & 500 & 9.5 & 779 \\
\hline & 100 & 4.0 & 108 & 14.0 & 515 & 9.7 & 811 \\
\hline
\end{tabular}

$\beta$ - heating rate; $w$ - weight loss; $T_{p}$ - peak temperature

\section{Relationship between conversion degree and temperature history}

From the above analysis, we could conclude that the main weight loss of oil shale during pyrolysis process occurred in the stage of decomposition of organic matter, so we chose this stage to study oil shale pyrolysis kinetics. According to TG curves shown in Fig. 4, it depicts the relationship between the reaction conversion degree and temperature of oil shale samples. The change of reaction rate is less striking at low temperatures and high temperatures, but the change is most pronounced at the medium temperatures. Taking OS1 at the heating rate of $10{ }^{\circ} \mathrm{C} / \mathrm{min}$ as an example, the reaction rate increases insignificantly with increasing temperatures when temperatures were less than $420{ }^{\circ} \mathrm{C}$ and more significantly at temperatures of $420-550{ }^{\circ} \mathrm{C}$, but less remarkably after $550{ }^{\circ} \mathrm{C}$. Moreover, heating rates have an important impact on the relationship between reaction rates and temperatures. The initial decomposition temperature for organic matter changes little with increasing heating rate, and decomposition usually occurs at $300-320{ }^{\circ} \mathrm{C}$. As heating rate increases, both the maximum decomposition rate and final decomposition temperature of organic matter shift to higher temperatures, as illustrated in Figures 1, 2 and 3. For example, the final decomposition temperature of organic matter for OS1 is $600{ }^{\circ} \mathrm{C}$ at $10{ }^{\circ} \mathrm{C} / \mathrm{min}$, but shifts to $660^{\circ} \mathrm{C}$ at $100{ }^{\circ} \mathrm{C} / \mathrm{min}$. Organic matter is considered to decompose completely up to $660{ }^{\circ} \mathrm{C}$. This can be attributed to variations in heat transfer due to changes in heating rate and shorter exposure time to a particular temperature at higher heating rates, as well as to decomposition kinetics under non-isothermal conditions. It can also be seen from Fig. 4 that, at higher heating rates, the same conversion of the solid reactant occurs at higher temperatures, similarly, a same temperature corresponds to lower conversions of decomposition at higher heating rates. 

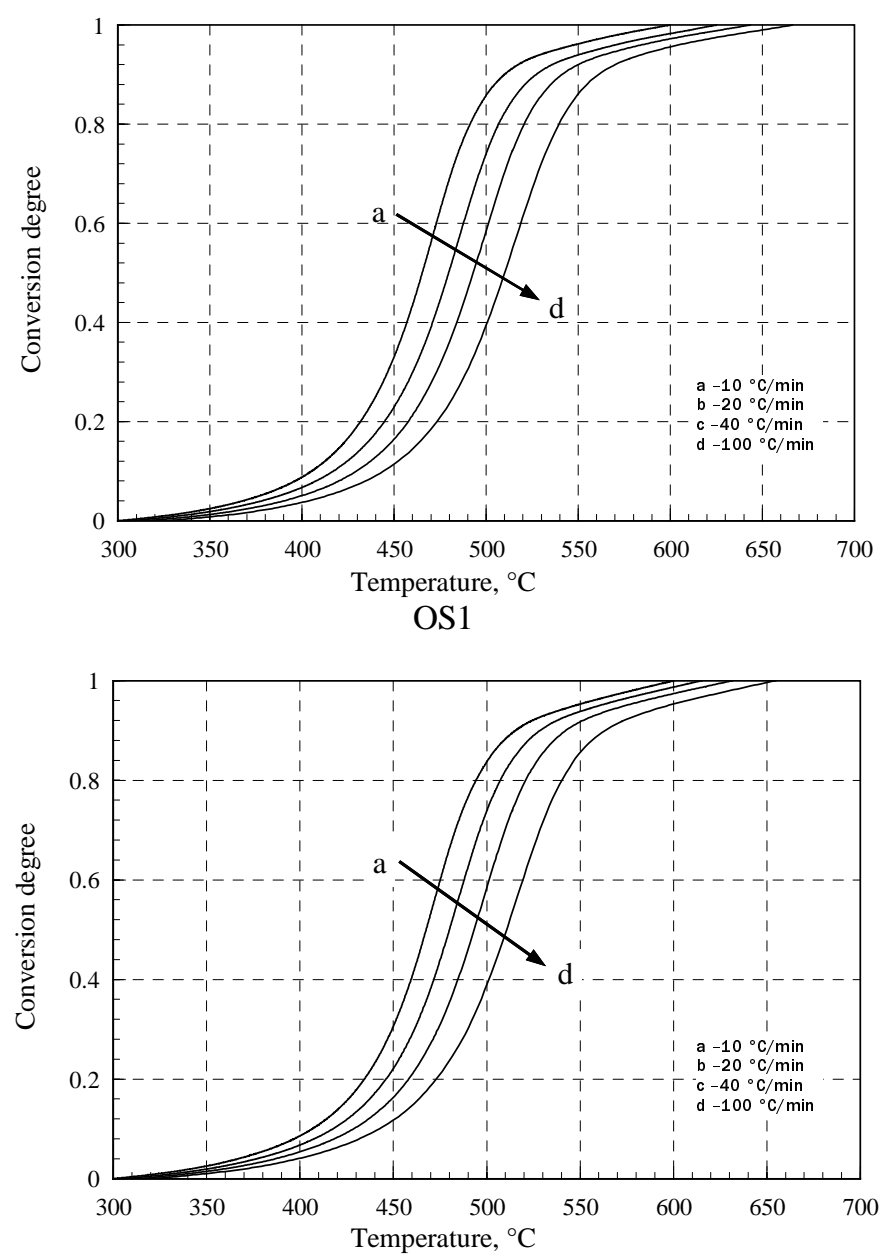

OS2

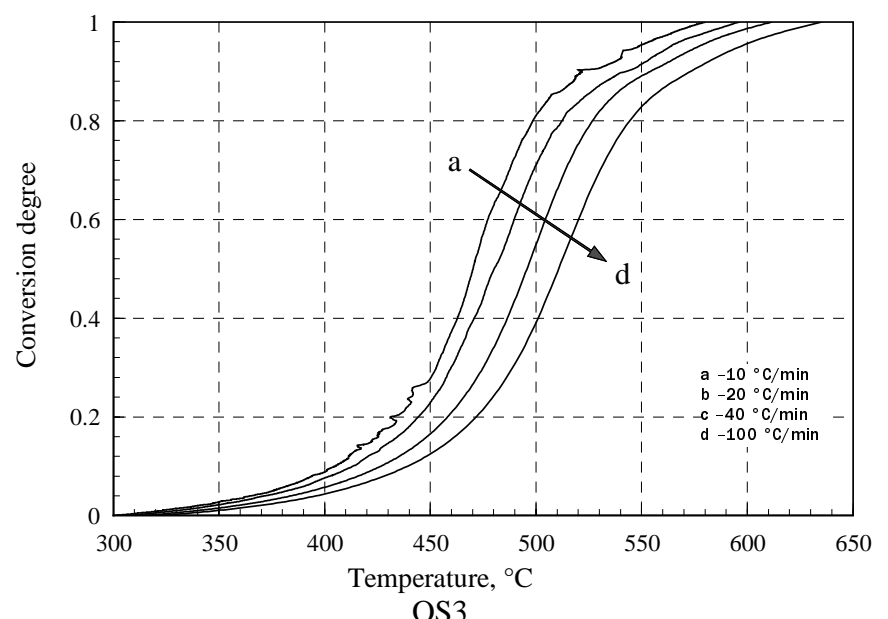

Fig. 4. The $\alpha-\mathrm{T}$ curves of oil shale samples at various heating rates. 


\section{Activation energy of oil shale pyrolysis}

99 conversion points for three oil shales at different heating rates are shown in Fig. 4. Friedman analyses, as described in Eq. (1) are applied in Fig. 5,

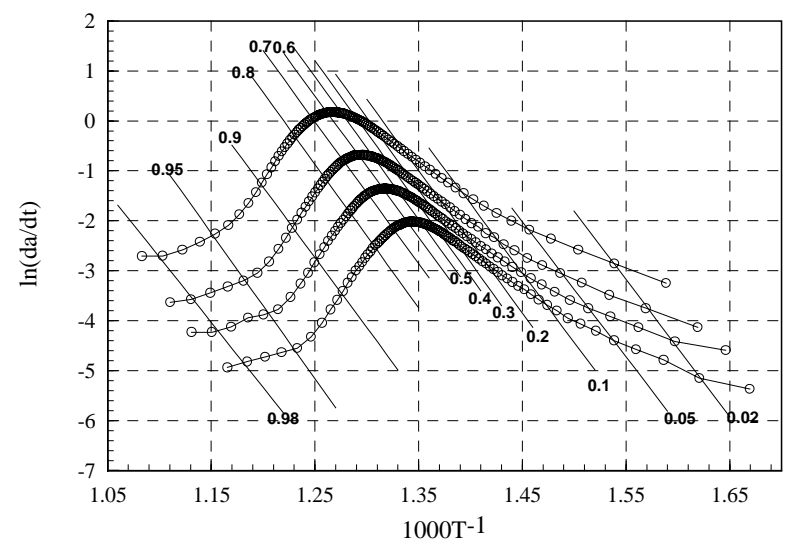

OS1
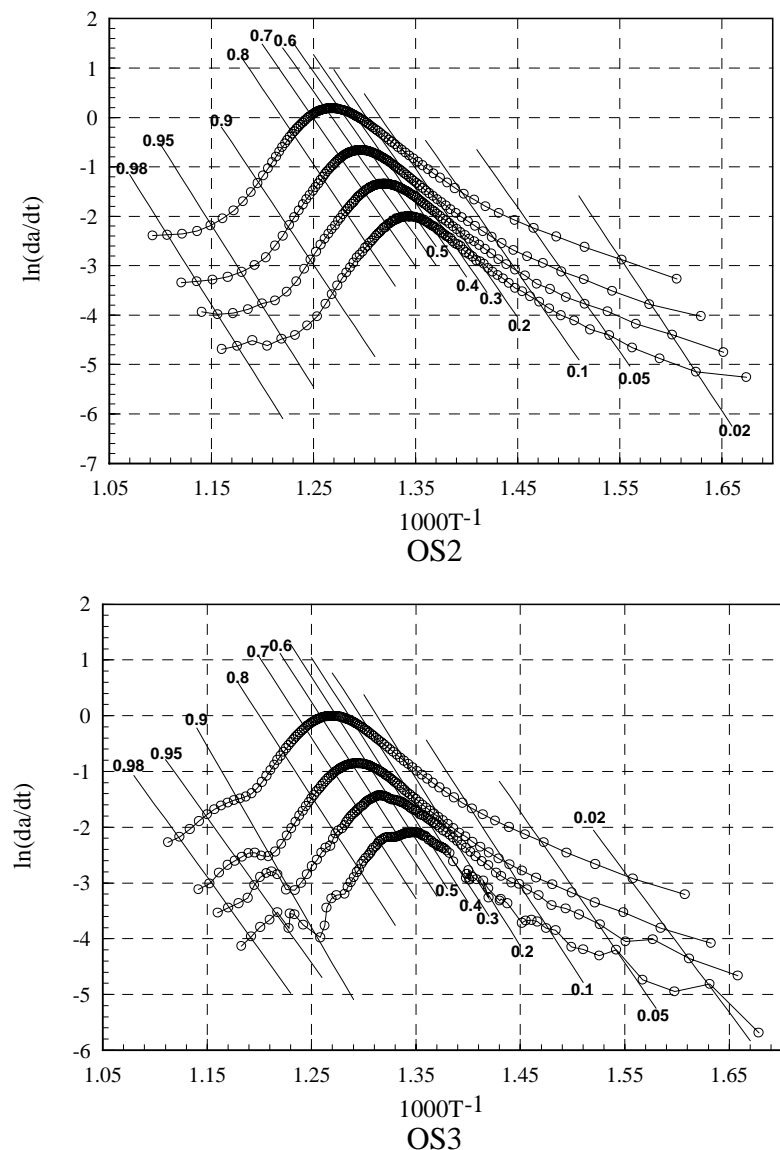

Fig. 5. Friedman analysis for pyrolysis of oil shale. 
where a plot of $\ln (\mathrm{d} \alpha / \mathrm{d} t)$ versus $1 / T$ produces a straight line with the slope of $(-E / R)$ used to yield activation energy. This is illustrated in Fig. 5 for all original data points. The points in the figures are collected at the different heating rates. Linear fittings were performed on each curve at a variety of conversions, yielding a series of fitted straight lines. The apparent activation energies are obtained from the slopes. Figure 5 implies that good correlation of the fittings has been achieved and the magnitude of correlation coefficient exceeds 0.99 , justifying the use of Friedman analysis method. Meanwhile, it can be seen that the slopes of fitting lines at the different conversions are roughly the same, indicating that the apparent activation energies, thus controlling mechanisms change only slightly with increasing conversions. Figure 6 illustrates the magnitude of variations in activation energy for the three oil shale samples as a function of conversion.

From Fig. 6 we can conclude that activation energy for the three oil shale samples is not a constant during the overall reaction, indicating that oil shale pyrolysis is a complicated multi-step reaction characterized by varying activation energies in different temperature ranges thus with different reaction mechanisms. However, it can be further discovered from this figure that the variations in activation energies for different oil shale samples are not significant. The variation of the activation energy shows scattering pattern in the conversion ranges of $0-0.1$ and $0.9-1$. Given that variations in activation energy are small in the conversion range of $0.1-0.9$, the mathematic mean values for three samples are $237.6,249.61$ and $242.67 \mathrm{~kJ} \cdot \mathrm{mol}^{-1}$, respectively. Compared to the results calculated with Coats-Redfern method [20], the magnitude of the activation energy is obviously much larger, probably indicating that the hypothetical model by Coats-Redfern method is not suitable for analysis of oil shale pyrolysis.

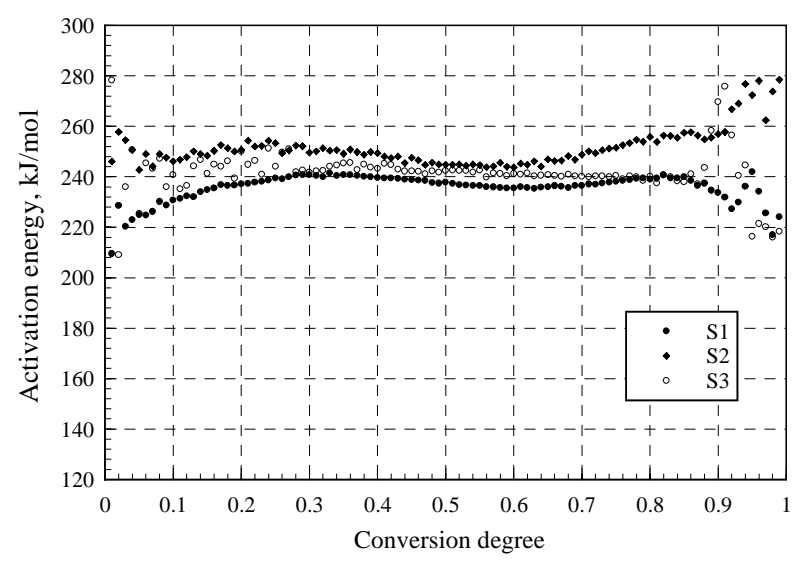

Fig. 6. The curves of $\mathrm{E}-\alpha$ for oil shale pyrolysis. 


\section{Determination of reaction model}

Because of complex structure and composition of oil shale, its pyrolysis actually consists of many elementary reactions occurring in parallel and in series. The extent of the overall pyrolysis reaction is just an apparent and integrated variable, making it impossible to correlate changes of apparent variables to elementary steps. Therefore, we are focusing only on general reaction mechanism in this study. As illustrated in Fig. 6, there is little change in activation energies across conversions of 0.1 to 0.9 , allowing us to consider activation energy a well-defined value leading to a well-defined reaction mechanism. The variables of the non-isothermal equations are further separated and integrated as follows [21]:

$$
G(\alpha)=\int_{0}^{\alpha} \frac{\mathrm{d} \alpha}{f(\alpha)}=\frac{A}{\beta} \int_{0}^{T} \exp \left(-\frac{E}{R T}\right) \mathrm{d} T=\frac{A E}{\beta R} P(u),
$$

where $u=E / R T, P(u)$ is approximated as $P(u) \cong \exp (-u) / u^{2}$ which is then inserted into Eq. (2). The equation of $Z(\alpha)$ can be presented below:

$$
Z(\alpha)=G(\alpha) f(\alpha)=\frac{R T^{2} \mathrm{~d} \alpha / \mathrm{d} t}{\beta E},
$$

where $Z(\alpha)$ is a defined function of conversion. The experimental data of $\alpha$, $\beta, T \mathrm{~d} \alpha / \mathrm{d} t$ and $E$ calculated by Friedman method at different heating rates are inserted into Eq. (3). $Z(\alpha)$ and $\alpha$ are then plotted in Fig. 7 that shows the experimental curves at different heating rates to fit into a single curve. Therefore, the same reaction mechanism is controlling the overall reaction process. Because oil shale pyrolysis is a complicated process with multiple reaction mechanisms, reaction order, defined as $f(\alpha)=(1-\alpha)^{n}$ is not suitable to describe the overall pyrolysis reaction. Sesták complex mechanism was, however, adopted below to investigate the pyrolysis mechanism.

The general form of Šesták-Berggren equation is [22] :

$$
f(\alpha)=a^{m}(1-\alpha)^{n}[-\ln (1-\alpha)]^{p},
$$

where $m, n$ and $p$ are constants, their derivatives imply the different reaction mechanisms: i.e., $a^{m},(1-\alpha)^{n}$ and $[-\ln (1-\alpha)]^{p}$ express the following three degradation mechanisms: diffusion mechanism, interface mechanism and nuclear mechanism [23]. A computer program has been compiled to calculate $G(\alpha)$. Functions $f(\alpha)$ and $G(\alpha)$ and are inserted into Eq. (3), optimum values of $m, n$ and $p$, are then fitted with the least square method. The results are shown in Table 3, and the fitting curves of three samples are plotted in Fig. 7. It shows that, according to the value of $P$, oil shale pyrolysis mainly attributes to the nuclear mechanism. 
Table 3. Optimum parameters for reaction mechanism of oil shale samples

\begin{tabular}{|c|c|c|c|}
\hline Samples & $m$ & $n$ & $p$ \\
\hline OS1 & -7.64 & 4.31 & 7.10 \\
OS2 & -7.94 & 4.55 & 7.40 \\
OS3 & -6.99 & 4.30 & 6.26 \\
\hline
\end{tabular}

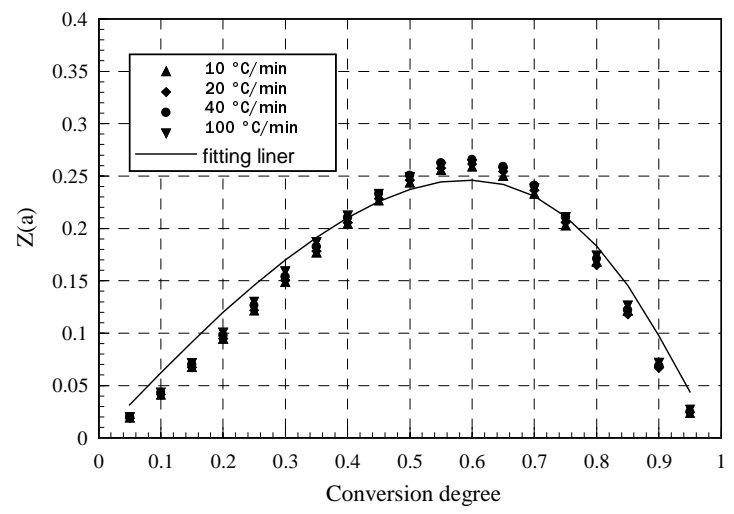

OS1

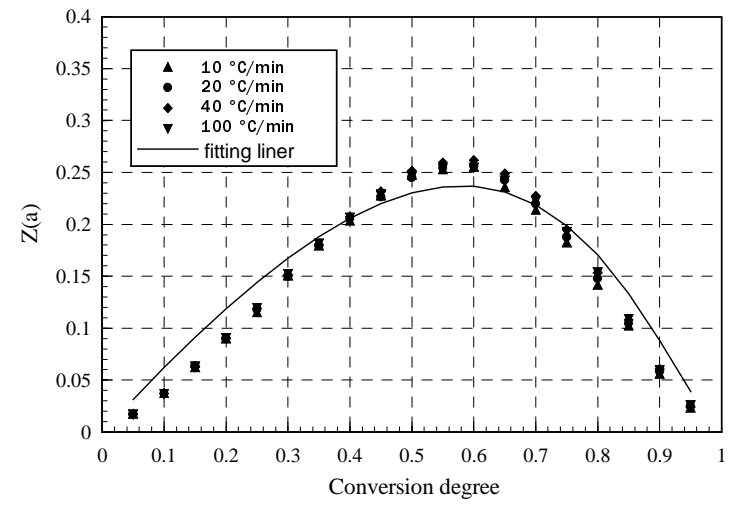

OS2

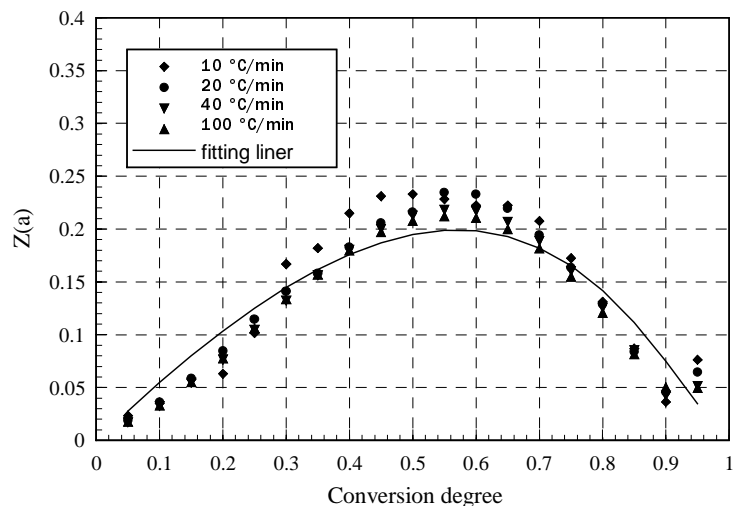

OS3

Fig. 7. Fitting lines for the pyrolysis reaction mechanism of oil shale. 


\section{Determination of the frequency factor}

By inserting the reaction model calculated into Eq. 1, one can obtain the frequency factor (also called the pre-exponential factor) from the intercept of the plot of $\ln (\mathrm{d} \alpha / \mathrm{d} t)-1 / T$. The results are shown in Fig. 8. It shows a similar variation trend as Fig. 6., i.e., the frequency factor is scattering in the ranges of $0-0.1$ and $0.9-1$, whereas there is no significant change in the range of $0.1-0.9$.

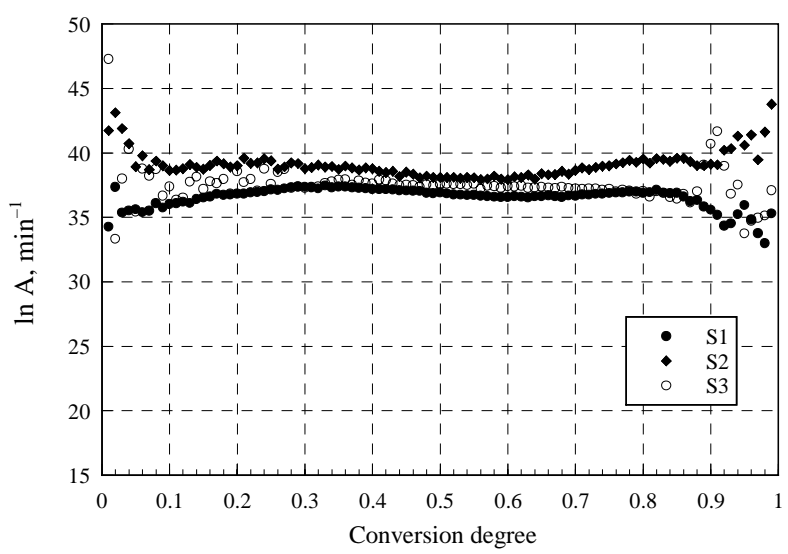

Fig. 8. Frequency factor of oil shale samples.

\section{Conclusions}

In this work, an experimental study on Huadian oil shale pyrolysis is presented. The following conclusions have been drawn:

1. Huadian oil shale pyrolyzes in three stages. The second stage, 200$600{ }^{\circ} \mathrm{C}$, accounts for the largest weight loss, which is attributed to the decomposition of hydrocarbon material.

2. Apparent activation energy for oil shale pyrolysis was calculated by Friedman method. In the conversion range of 0.1-0.9, activation energies change slightly, with the mean values for OS1, OS2 and OS3 being $237.6,249.61$ and $242.67 \mathrm{~kJ} \cdot \mathrm{mol}^{-1}$, and their standard deviations are $2.3,3.86$ and 4.61 , respectively.

3. Šesták complex mechanism was applied to elucidate pyrolysis control mechanism. The results show that oil shale pyrolysis is not a simple first-order reaction. 


\section{Acknowledgments}

The authors are grateful for financial support from the Key Project of Research Program of Jilin Province (20065022).

\section{REFERENCES}

1. Kök, M. V. Thermal investigation of Seyitomer oil shale // Thermochim. Acta. 2001. Vol. 369, No. 1-2. P. 149-155.

2. Wang, Q., Bai, J. R., Sun, B.Z., Sun, J. Strategy of Huadian oil shale comprehensive utilization // Oil Shale. 2005. Vol. 22, No. 3. P. 305-316.

3. Yu, H. L., Jiang, X. M. Study of pyrolysis property of Huadian oil shale // Journal of Fuel Chemistry and Technology. 2001. Vol. 29, No. 5. P. $450-453$ [in Chinese].

4. Ran, J. Y., Niu, B., Zhang, L. Study on general combustion performance and kinetic characteristics of combustion of coal residue // Proceedings of the CSEE. 2006. Vol. 26, No. 15. P. 58-62 [in Chinese].

5. Bai, J. R., Wang, Q., Hu, A. J., Sun, B. Z., Li, S. H. The pyrolysis characteristics of Maoming oil shales // Journal of Northeast Dianli University. 2006. Vol. 26, No. 2. P. 73-78 [in Chinese].

6. Hu, R. Z., Shi, Q.Z. Dynamics of Thermal Analysis. - Beijing: Science Press, 2001 [in Chinese].

7. Kök, M. V., Senguler, I., Hufnagel, H., Sonel, N. Thermal and geochemical investigation of Seyitomer oil shale // Thermochim. Acta. 2001. Vol. 371, No. 1-2. P. 111-119.

8. Kök, M. V., Pamir, R. Pyrolysis kinetics of oil shales determined by DSC and TG/DTG // Oil Shale. 2003. Vol. 20, No. 1. P. 57-68.

9. Jaber, J. O., Probert, S. D. Non-isothermal thermogravimetry and decomposition kinetics of two Jordanian oil shales under different processing conditions // Fuel Process. Technol. 2000. Vol. 63, No. 1. P. 57-70.

10. Khrasiha, Y. H., Shabib, I. M. Thermal analysis of shale oil using thermogravimetry and differential scanning calorimetry // Energy Convers. Manage. 2002. Vol. 43, No. 2. P. 229-239.

11. Jiang, X. M., Liu, D. C., Zheng, C. G. Study of oil shale combustion characteristics by thermal analysis method // Proceedings of the CSEE. 2001. Vol. 21, No. 8. P. 55-59 [in Chinese].

12. Wang, Q., Wu, X. H., Sun, B. Z., Bai, J. R., Sun, J. Combustion reaction kinetics study of Huadian oil shale semi-coke // Proceedings of the CSEE. 2006. Vol. 26, No. 7. P. $29-34$ [in Chinese].

13. Brown, M. E., Maciejewski, M., Vyazovkin, S. et al. Computational aspects of kinetic analysis. Part A: The ICTAC kinetics project-data, methods and results // Thermochim. Acta. 2000. Vol. 355, No. 1-2. P. 125-143.

14. Maciejewski, M. Computational aspects of kinetic analysis. Part B: The ICTAC kinetics project - the decomposition kinetics of calcium carbonate revisited, or some tips on survival in the kinetic minefield // Thermochim. Acta. 2000. Vol. 355, No. 1-2. P. 145-154.

15. Vyazovkin, $S$. Computational aspects of kinetic analysis. Part C. The ICTAC 
kinetics project - the light at the end of the tunnel? // Thermochim. Acta. 2000. Vol. 355, No. 1-2. P. 155-163.

16. Burnham, A. K. Computational aspects of kinetic analysis. Part D: The ICTAC kinetics project - multi-thermal-history model-fitting methods and their relation to isoconversional methods // Thermochim. Acta. 2000. Vol. 355, No. 1-2. P. $165-170$.

17. Roduit, B. Computational aspects of kinetic analysis. Part E: The ICTAC kinetics project - numerical techniques and kinetics of solid state processes // Thermochim. Acta. 2000. Vol. 355, No. 1-2. P. 171-180.

18. Vyazovkin, S., Wight, C. A. Model-free and model-fitting approaches to kinetic analysis of isothermal and nonisothermal data // Thermochim. Acta. 1999. Vol. 340-341. P. 53-68.

19. Williams, P. T., Ahmad, N. Investigation of oil-shale pyrolysis processing conditions using thermogravimetric analysis // Appl. Energy. 2000. Vol. 66, No. 2. P. 113-133.

20. Wang, Q., Sun, B. Z., Hu, A. J., Bai, J. R., Li, S. H. Pyrolysis characteristics of Huadian oil shales // Oil Shale. 2007. Vol. 24, No. 2. P. 147-157.

21. Friedman, H. L. A quick, direct method for the determination of activation energy from thermogravimetric data// J. Polym. Lett. 1966. Vol. 4, No. 5. P. 323-328

22. Šesták, J., Berggren, G. Study of the kinetics of the mechanism of solid-state reactions at increasing temperatures // Thermochim. Acta. 1971. Vol. 3, No. 1. P. $1-12$.

23. Feng, Y. J., Si, Y. Q., He, D. M. Kinetics of thermal decomposition of solid by thermal analysis // Polymer Materials Science and Engineering. 1997. Vol. 13, No. 2. P. 30-34 [in Chinese].

Presented by Jialin Qian

Received November 7, 2008 